\title{
Electroreactivity of isopropanol on platinum in acids studied by DEMS and FTIRS
}

\author{
E. Pastor ${ }^{*}$, S. González, A.J. Arvia ${ }^{1}$ \\ Departamento de Química Física, Universidad de La Laguna, 38205 Tenerife, Spain
}

Received 6 March 1995; in revised form 1 May 1995

\begin{abstract}
The reactivity of isopropanol on polycrystalline $\mathrm{Pt}$ in acid solutions was investigated using in-situ Fourier transform IR spectroscopy (FTIRS) and on-line differential electrochemical mass spectrometry (DEMS). The electro-oxidation products are acetone and $\mathrm{CO}_{2}$; the former is observed when isopropanol is present in the bulk of the solution, and the latter is produced from strongly adsorbed species. Both bulk and adsorbed isopropanol electro-reduction yield propane. $\mathrm{H}-\mathrm{D}$ exchange is observed during propane formation when the reaction takes place in a $\mathrm{D}_{2} \mathrm{O}+\mathrm{DClO}_{4}$ solution. This observation suggests the formation of adsorbates bonded to the surface through the $\mathrm{C} \alpha$ atom of the isopropanol molecule. FTIR spectra of adsorbed species show the presence of $-\mathrm{CH}_{3}$ and $-\mathrm{COH}$ groups. The most probable adsorbate structures are $\left(\mathrm{CH}_{3}-\mathrm{C}-\mathrm{CH}_{3}\right) \mathrm{Pt},\left(\mathrm{CH}_{3}-\mathrm{CH}-\mathrm{CH}_{3}\right) \mathrm{Pt}$ and $\left(\mathrm{CH}_{3}-\mathrm{COH}-\mathrm{CH}_{3}\right) \mathrm{Pt}$, presumably accompanied by $\left(\mathrm{CH}{ }_{3}-\mathrm{CO}-\right.$ $\left.\mathrm{CH}_{3}\right) \mathrm{Pt}$.
\end{abstract}

K' ${ }^{\prime} y w o r d s:$ IR spectroscopy; Differential electrochemical mass spectrometry; Electroreactivity; Isopropanol

\section{Introduction}

In a previous series of papers, the electrochemical behavior of $C_{3}$ primary alcohols, namely n-propanol [1], allyl alcohol [2] and propargyl alcohol [3], has been studied on polycrystalline $\mathrm{Pt}$ electrodes in acid solution by using electrochemical methods combined with in-situ Fourier transform IR spectroscopy (FTIRS) [4] and differential electrochemical mass spectrometry (DEMS) [5]. On the basis of these studies, reaction pathways have been proposed for the electrochemical oxidation and reduction of these alcohols on Pt in acids [1-3]. It was also found that the investigation of a secondary $\mathrm{C}_{3}$ alcohol, such as isopropanol, could help to improve our understanding of further aspects of the electroreactivity of alcohols with a $\mathrm{C}_{3}$ chain on $\mathrm{Pt}$ in acids.

The electrochemical behavior of isopropanol on $\mathrm{Pt}$ in acid solutions has been the subject of a number of investigations [6-17]. There is general agreement on the fact that there is negligible cleavage of $\mathrm{C}-\mathrm{C}$ bonds during the adsorption of isopropanol on polycrystalline $\mathrm{Pt}$ [6-

\footnotetext{
* Corresponding author.

' Permanent address: INIFTA, La Plata, Argentina.
}

$8,10,11,17]$, and that no absorption bands due to $\mathrm{CO}$ adsorbed species are observed in the FTIR spectra when isopropanol is present in the bulk of the solution [12-15]. A $\mathrm{CH}_{3} \mathrm{COHCH}_{3}$ structure has been proposed for the adsorbate on Pt $[7,8,10,11,17]$. Furthermore, electron energy loss spectroscopy (EELS) data of isopropanol adsorbed on $\mathrm{Pt}(111)$ at $-0.1 \mathrm{~V}$ vs. $\mathrm{Ag}|\mathrm{AgCl}| 1 \mathrm{M} \mathrm{KCl}$ demonstrate the disappearance of the hydroxyl hydrogen during adsorption and the formation of alkoxide species [16]. In contrast with these conclusions, the absence of chemisorbed species on Pt during isopropanol electro-oxidation has been suggested [9].

Most adsorbed residues from isopropanol on $\mathrm{Pt}$ are desorbed by electro-reduction $[10,11]$. A mechanism involving desorption as isopropanol has been proposed for this reaction [10]. FTIRS studies have shown that $\mathrm{CO}_{2}$ and acetone are the final products of isopropanol electro-oxidation [12-15], in agreement with preliminary DEMS data [17]. However, different reaction pathways have been proposed for the appearance of these products. Thus a reaction involving successive dehydrogenation steps with the formation of an acetone intermediate has been discussed for the electro-oxidation of isopropanol on $\mathrm{Pt}$ yielding $\mathrm{CO}_{2}$ [14]. Conversely, different parallel reaction pathways for isopropanol oxidation on Pt in acids have been postulated 
for the production of $\mathrm{CO}_{2}$ and acetone $[7,12,13]$. Recently, from a kinetic study of the oxidation of isopropanol on $\mathrm{Pt}$ by means of in-situ time-resolved FTIRS, the dehydrogenation was assigned as the main and fastest reaction for the overall oxidation of isopropanol on Pt [15].

At this stage it can be concluded that the adsorption mechanism of isopropanol on $\mathrm{Pt}$ in acid is far from proven. This situation encourages further investigation of the subject particularly oriented to clarify the electrode-alcohol interactions involved in the reduction and oxidation processes.

A probable reaction pathway for the above processes derived from electrochemical methods, together with DEMS and FTIRS, following experimental procedures described in preceding publications [1-3], is presented in this article.

\section{Experimental}

\subsection{Chemicals and instrumentation}

Solutions were prepared from Millipore MilliQ * water and analytical grade chemicals. Isopropanol concentration was varied in the 0.01-1 $\mathrm{M}$ range. The base solution for FTIRS was $0.1 \mathrm{M} \mathrm{HClO}_{4}$, whereas either $0.05 \mathrm{M} \mathrm{H}_{2} \mathrm{SO}_{4}$ or $0.1 \mathrm{M} \mathrm{HClO}_{4}$ was employed for DEMS. Argon $(99.998 \%)$ and nitrogen $(99.999 \%)$ were used to deaerate solutions for DEMS and FTIRS respectively. These gases continuously flowed over the solution during the experiments. All measurements were performed at room temperature.

Volatile products were detected using DEMS. The mass-current response was recorded almost simultaneously with the cyclic voltammogram. Most details of the experimental procedure have been described elsewhere [1]. The working electrode (real area, $10 \mathrm{~cm}^{2}$ ) was prepared by sputtering Pt on a PTFE membrane interfacing the electrochemical system and the mass spectrometer. The counterelectrode was a Pt wire $(0.5 \mathrm{~mm}$ in diameter $)$. Measurements were performed at $0.01 \mathrm{~V} \mathrm{~s}^{-1}$

The FTIR spectrometer was a Digilab FTS-40 provided with a mercury-cadmium telluride (MCT) detector. A glass flow cell $\left(6 \mathrm{~cm}^{3}\right)$ with a $\mathrm{CaF}_{2}$ window and a flat $\mathrm{Pt}$ ring $0.5 \mathrm{~cm}$ thick and $2.8 \mathrm{~cm}$ in diameter were employed. The working electrode was a polycrystalline Pt disk $(1 \mathrm{~cm}$ in diameter). Experimental details including the cell design have been given in previous publications $[1,18]$.

A reversible hydrogen electrode (RHE) in the base solution was used as reference electrode. Prior to each measurement, the working electrode was activated in the base solution by applying repetitive potential cycles between the threshold potentials of hydrogen and oxygen evolution until a reproducible voltammogram was obtained.

\subsection{Experimental procedure for isopropanol adsorption}

Isopropanol adsorption experiments were performed in the flow cell under constant-potential conditions. Thus, after the activation of the working electrode in the base solution, the potential was held at $E_{\text {ad }}\left(0.05 \mathrm{~V} \leq E_{\text {ad }} \leq 0.40\right.$ $\mathrm{V})$ and then $0.05 \mathrm{M}$ isopropanol in base solution was added to the base solution in the cell. Simultaneously, the corresponding current transient was recorded for $5 \mathrm{~min}$ and then the isopropanol-containing solution in the cell was replaced by the base solution. Finally, DEMS or FTIRS measurements were performed. Procedures are described in the next section.

\section{Results}

\subsection{DEMS data}

\subsubsection{Bulk reactions}

The voltammogram of $\mathrm{Pt}$ in $0.05 \mathrm{M}$ isopropanol +0.1

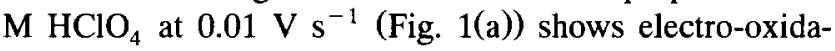

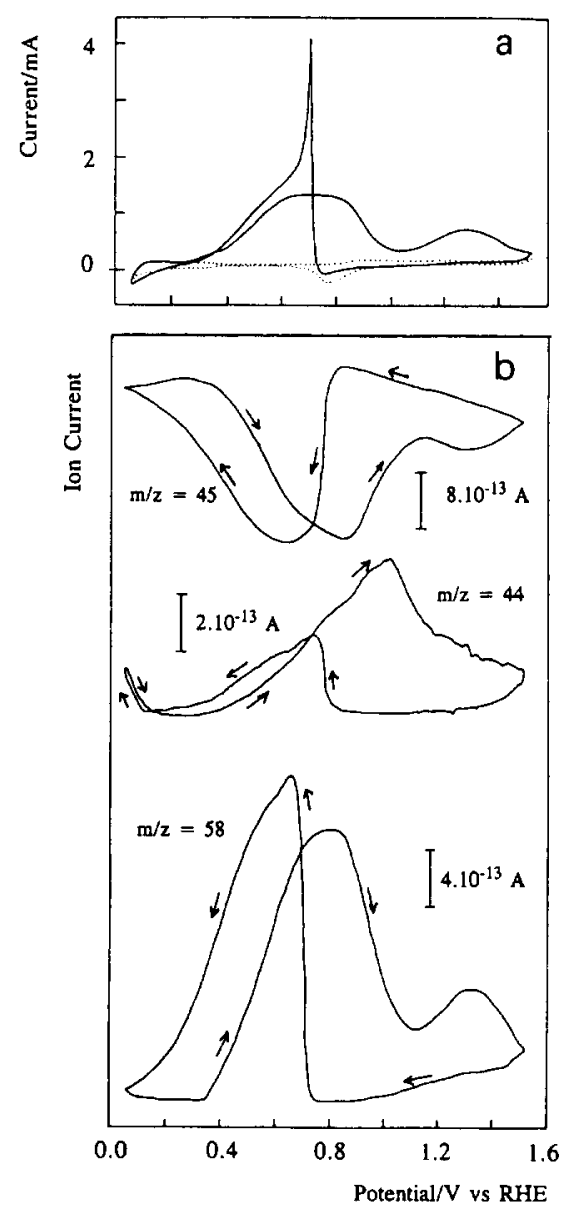

Fig. 1. (a) Cyclic voltammogram of porous $\mathrm{Pt}$ in $0.05 \mathrm{M}$ isopropanol +0.1 $\mathrm{M} \mathrm{HClO}_{4}\left(v=0.01 \mathrm{~V} \mathrm{~s}^{-1}\right)$; (b) mass signal cyclic voltammograms for $m / z=45\left(\left[\mathrm{CH}_{3} \mathrm{CHOH}\right]^{+}\right), m / z=44\left(\left[\mathrm{CO}_{2}\right]^{++}\right.$and $\left.\left[\mathrm{C}_{3} \mathrm{H}_{8}\right]^{+}\right)$and $m / z=58\left(\left[\mathrm{CH}_{3} \mathrm{COCH}_{3}\right]^{+}\right)$. 
tion current peaks centered at 0.70 and $1.30 \mathrm{~V}$. During the reverse potential scan, a sharp electro-oxidation peak followed by a broad hump is observed in the cyclic voltammogram at potentials below $0.75 \mathrm{~V}$. Mass signals obtained during the voltammetric scan for selected $\mathrm{m} / z$ values are shown in Fig. 1(b). The ratios $m / z=44$ and $m / z=58$ correspond to $\mathrm{CO}_{2}$ and acetone radical cations $\left(\mathrm{M}^{+}\right)$ respectively. Although the $m / z=58$ signal could be related to the production of propanal, this possibility should be disregarded as the $m / z=29$ signal $\left([\mathrm{COH}]^{+}\right.$, not shown in the figure), i.e. the main peak in the mass spectrum of propanal, is very small compared with that for $m / z=58$.

The onset of $\mathrm{CO}_{2}$ production, shown by the $m / z=44$ signal during the positive-going potential scan, occurs around $0.40 \mathrm{~V}$ and this signal increases steadily, reaching a maximum value at $1.01 \mathrm{~V}$ with a shoulder at $0.78 \mathrm{~V}$. During the negative-going scan, $\mathrm{CO}_{2}$ production is strongly inhibited until the Pt oxide layer is partially reduced. Then the $m / z=44$ signal increases sharply, producing a spike at $0.73 \mathrm{~V}$, and subsequently decreases to a minimum at about $0.20 \mathrm{~V}$. In the reverse potential scan the height of the $m / z=44$ signal is only half the signal height recorded in the positive-going potential scan.

The $m / z=58$ signal related to acetone formation appears when the positive-going potential scan exceeds 0.35 $\mathrm{V}$. The height of this signal increases very fast, reaching a maximum value at $0.78 \mathrm{~V}$, and then decreases, in contrast with the $\mathrm{CO}_{2}$ signal $(m / z=44)$ in this potential region. A second peak related to acetone production appears around $1.32 \mathrm{~V}$, i.e. in the potential range where $\mathrm{Pt}$ surface is already covered by oxide. During the reverse potential scan, as for $\mathrm{CO}_{2}$, acetone production starts immediately after the electroreduction of $\mathrm{Pt}$ oxide. However, in this case the height of the signal at $0.64 \mathrm{~V}$ is greater than that at $0.78 \mathrm{~V}$ during the preceding potential scan. Therefore the sharp peak observed in the cyclic voltammogram for the negative-going potential scan is probably related to the formation of acetone. The acetone to $\mathrm{CO}_{2}$ yield ratio calculated from tabulated fragmentation data [19] is about 8.

The consumption of isopropanol can be followed through the $m / z=45$ signal which corresponds to $\left[\mathrm{CH}_{3} \mathrm{CHOH}\right]^{+}$, the main fragment expected from the isopropanol molecule. The minimum heights of this signal (at $0.80 \mathrm{~V}$ and $0.63 \mathrm{~V}$ during the positive-going and negative-going potential scans respectively) correlate with the maxima of acetone formation.

The increase in the $m / z=44$ signal at potentials below $0.15 \mathrm{~V}$ is related to the radical cation $\mathrm{M}^{+}$of propane, which appears as the only electroreduction product. This assignment is confirmed by the presence of signals for $m / z=15,29$ and 30 (not shown in the figure) which correspond to the fragmentation of propane in the ion chamber of the mass spectrometer.

No significant influence of the base electrolyte on either the yield or the potential range of formation of the products was observed.

\subsubsection{Adsorbed species}

The electrochemical behavior of adsorbates was investigated for different values of $E_{\mathrm{ad}}$. For $E_{\mathrm{ad}}=0.05 \mathrm{~V}$, the addition of alcohol produces neither a current transient nor adsorbate formation on Pt. Conversely, for $E_{\text {ad }}=0.25$ and $E_{\text {ad }}=0.35 \mathrm{~V}$, anodic current transients are observed. For $E_{\mathrm{ad}}=0.25 \mathrm{~V}$, the current transient decays to zero after 2 min; the charge density involved in this process is about $100 \mu \mathrm{C} \mathrm{cm}^{-2}$. Part of this current transient can be explained in terms of the desorption of the $\mathrm{H}$ atoms replaced by isopropanol molecules. The charge involved in the total displacement of hydrogen at $E_{\text {ad }}=0.25 \mathrm{~V}$, estimated from the cyclic voltammograms, is about $45 \mu \mathrm{C} \mathrm{cm}^{-2}$. The rest of the charge (55 $\mu \mathrm{C} \mathrm{cm}^{-2}$ ) is probably related to isopropanol deprotonation.

At $E_{\mathrm{ad}}=0.35 \mathrm{~V}$ a residual anodic current is observed after $5 \mathrm{~min}$ and the total charge density involved is ca. 570 $\mu \mathrm{C} \mathrm{cm}{ }^{-2}$. The fact that the charge density derived from the current transient is much larger than the monolayer charge density for $\mathrm{H}$ adatoms on polycrystalline $\mathrm{Pt}$ (210 $\mu \mathrm{C} \mathrm{cm}^{-2}$ ), together with the presence of a residual current after 5 min, leads to the conclusion the electro-oxidation of bulk isopropanol has already occurred at this potential. It should be assumed that $0.35 \mathrm{~V}$ corresponds to the threshold potential for acetone production (Fig. 1(b)).
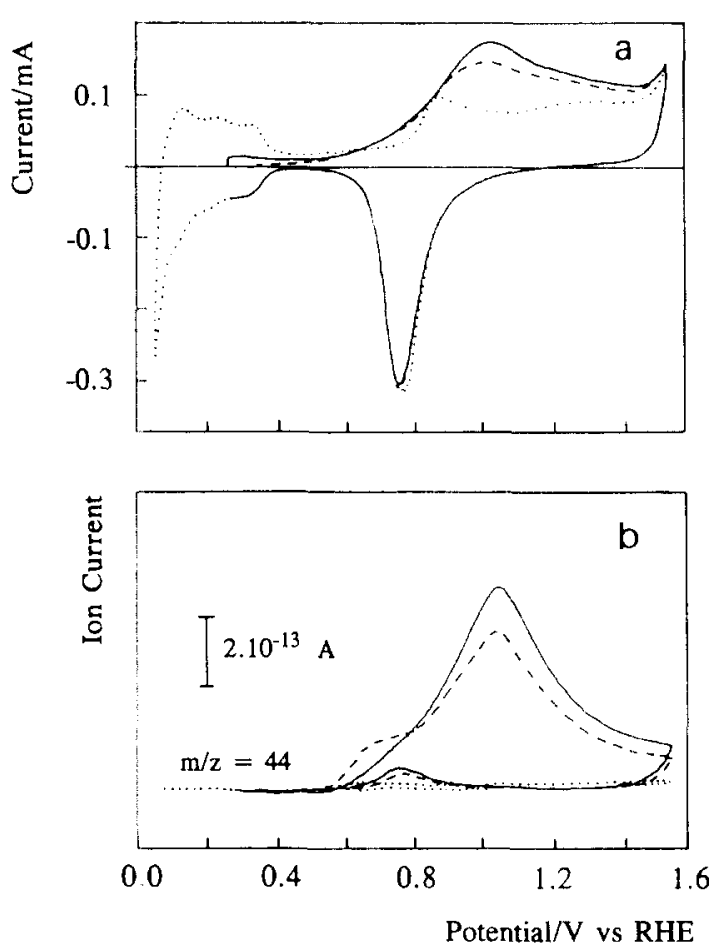

Fig. 2. (a) Cyclic voltammograms of isopropanol adsorbates in $0.1 \mathrm{M}$ $\mathrm{HClO}_{4}$ on porous $\mathrm{Pt}\left(v=0.01 \mathrm{~V} \mathrm{~s}^{-1}\right)$; (b) mass signal cyclic voltammograms for $m / z=44\left(\left[\mathrm{CO}_{2}\right]^{+}\right)$for different adsorption potentials $\left(\cdots \cdots E_{\mathrm{ad}}=0.05 \mathrm{~V} ; \longrightarrow E_{\mathrm{ad}}=0.25 \mathrm{~V} ;-\longrightarrow E_{\mathrm{ad}}=0.35 \mathrm{~V}\right)$. 
The direct electro-oxidation of adsorbed residues formed at $E_{\text {ad }}=0.25 \mathrm{~V}$ and $E_{\text {ad }}=0.35 \mathrm{~V}$ commences at $0.55 \mathrm{~V}$ irrespective of $E_{\text {ad }}$ (Fig. 2). A large $\mathrm{CO}_{2}$ signal at $1.04 \mathrm{~V}$ is recorded for $E_{\mathrm{ad}}=0.25 \mathrm{~V}$, whereas two different contributions at $0.69 \mathrm{~V}\left(E_{\mathrm{p} 1}\right)$ and $1.04 \mathrm{~V}\left(E_{\mathrm{p} 2}\right)$ are observed for $E_{\mathrm{ad}}=0.35 \mathrm{~V}$. During the first negative-going potential scan, the electro-oxidation reaction gives a third signal $\left(E_{\mathrm{p} 3}\right)$ with a maximum at $0.73 \mathrm{~V}$, i.e. just when free $\mathrm{Pt}$ surface domains begin to appear.

The complete electro-oxidation of isopropanol adsorbates is accomplished after two or three potential cycles up to $1.55 \mathrm{~V}$, irrespective of the base electrolyte. On the second cycle, two peaks are recorded at about $0.78 \mathrm{~V}$ and $1.03 \mathrm{~V}$ (Fig. 3).

Potentials related to the peaks of the first scan of the mass signal for $\mathrm{CO}_{2}(m / z=44)$ and the electro-oxidation charge obtained from the CVs for different $E_{\text {ad }}$ are given in Table 1. It should be noted that, as far as peak potential values are concerned, most reliable data result from the mass current response. For a given $E_{\text {ad }}$, there is a clear influence of the base solution composition on the value of $E_{\mathrm{p} 1}$. The latter is more positive in aqueous $\mathrm{H}_{2} \mathrm{SO}_{4}$ than in aqueous $\mathrm{HClO}_{4}$. This effect has also been observed for propanol adsorbate electro-oxidation, and in that case stabilization of the oxygen-containing adsorbates through the
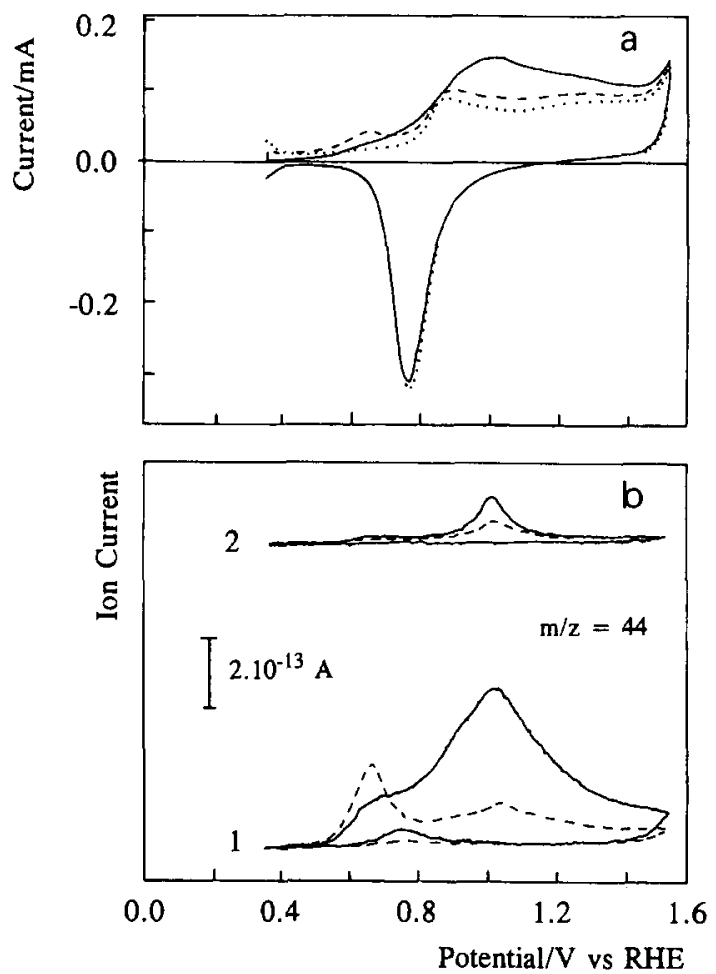

Fig. 3. (a) Cyclic voltammograms of isopropanol adsorbates in $0.1 \mathrm{M}$ $\mathrm{HClO}_{4}$ on porous $\mathrm{Pt}\left(v=0.01 \mathrm{~V} \mathrm{~s}^{-1}\right)(\ldots$ base electrolyte); (b) mass signal cyclic voltammograms for $m / z=44\left(\left[\mathrm{CO}_{2}\right]^{+}\right)(-$direct electro-oxidation;

- - electro-oxidation after four cycles between $0.35 \mathrm{~V}$ and $0.05 \mathrm{~V}$; 1 and 2 denote the first and the second cycles respectively).
Table 1

$E_{\mathrm{p} 1}, E_{\mathrm{p} 2}$ and $E_{\mathrm{p} 3}$ potential peaks from the mass signal for $m / z=44$ in the first electro-oxidation cycle of isopropanol adsorbates formed at $E_{\text {ad }}$ on $\mathrm{Pt}$

\begin{tabular}{llrllll}
\hline Base electrolyte & $E_{\mathrm{ad}} / \mathrm{V}$ & $N_{\mathrm{H}}$ & $E_{\mathrm{p} 1} / \mathrm{V}$ & $E_{\mathrm{p} 2} / \mathrm{V}$ & $E_{\mathrm{p} 3} / \mathrm{V}$ & $q_{\mathrm{ox}} / \mathrm{mC}$ \\
\hline $0.05 \mathrm{M} \mathrm{H}_{2} \mathrm{SO}_{4}$ & 0.35 & 0 & 0.80 & 1.06 & 0.73 & 2.75 \\
& & 4 & 0.70 & 1.05 & 0.74 & 1.56 \\
& & 6 & 0.71 & 1.05 & 0.74 & 0.96 \\
& & 10 & 0.71 & 1.05 & 0.74 & 0.95 \\
& 0.25 & 0 & - & 1.08 & 0.73 & 3.85 \\
$0.1 \mathrm{M} \mathrm{HClO}_{4}$ & 0.35 & 0 & 0.69 & 1.04 & 0.75 & 3.03 \\
& & 4 & 0.65 & 1.03 & - & 1.05 \\
& & 10 & 0.67 & 1.04 & - & 0.92 \\
& 0.25 & 0 & - & 1.04 & 0.75 & 3.85 \\
& & 4 & 0.66 & 1.04 & - & 0.75 \\
\hline
\end{tabular}

$N_{\mathrm{H}}$, numbers of cycles in the $\mathrm{Pt}-\mathrm{H}$ potential region.

$q_{\mathrm{ox}}$, electro-oxidation charge of isopropanol adsorbates determined from cyclic voltammograms.

Real area of the working electrode, $10 \mathrm{~cm}^{2}$.

formation of an anion and water cluster network was suggested [1].

The main desorption product of the electroreduction of isopropanol adsorbate, as well as that of the bulk alcohol, is propane. The formation of this product takes place at $E<0.20 \mathrm{~V}$, i.e. within the hydrogen adsorption potential range (Fig. 4(a)). In this case, the first cyclic voltammogram shows a cathodic voltammetric charge that is greater than the anodic voltammetric charge. This charge difference can be attributed to hydrogenation of the adsorbate. Otherwise, the signal for $m / z=44$ reveals that the largest amount of propane appears during the first incursion in the hydrogen adsorption region and gradually decays in the subsequent potential cycles (Fig. 4(b)). Accordingly, it is reasonable to assume most of the $\mathrm{C}_{3}$ structure of isopropanol remains in the adsorbates formed on $\mathrm{Pt}$.

It should be mentioned that no change in the $m / z=45$ baseline signal with the applied potential was observed. This indicates that, in contrast with conclusions drawn by other authors [10], no isopropanol is formed during adsorbate desorption.

The electro-oxidation of adsorbates remaining on the surface after four potential incursions in the hydrogen adsorption region is shown by the dashed line in Fig. 3 . Two broad peaks are observed, the first in the $0.65-0.73 \mathrm{~V}$ range which depends on $E_{\text {ad }}$ and the base solution composition and the second at about $1.05 \mathrm{~V}$. The potential region for these contributions coincides with that of the oxidation of acetone adsorbates [20]. Therefore it appears that adsorbed residues with similar structures are formed for isopropanol and acetone on Pt.

For $E_{\mathrm{ad}}=0.25 \mathrm{~V}, 80 \%$ of the initial charge is lost after four potential cycles between 0.25 and $0.05 \mathrm{~V}$ at $v=0.01$ 


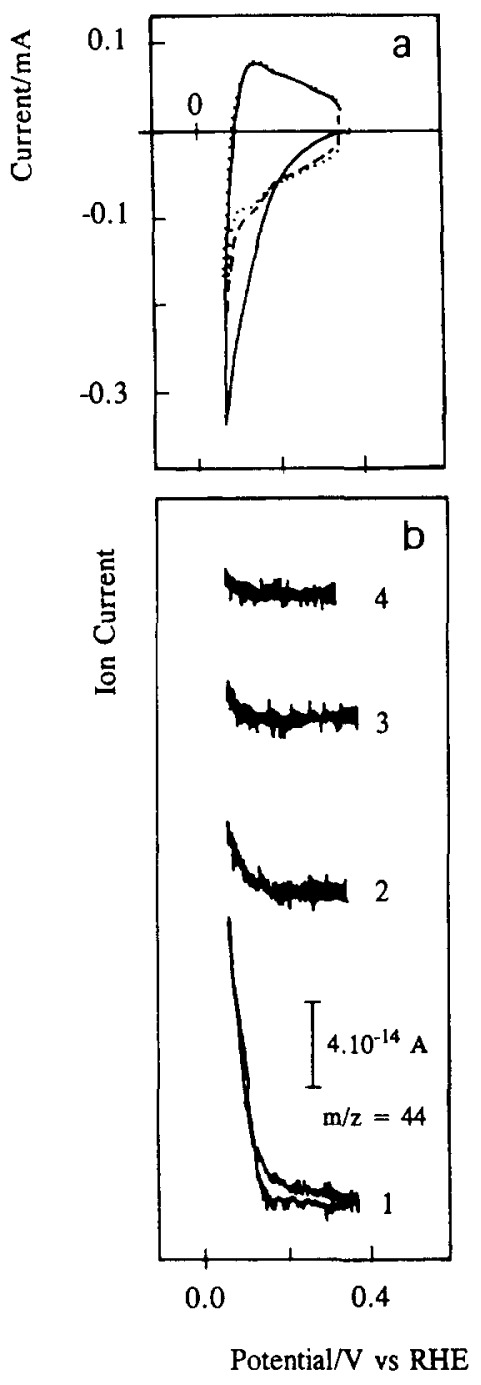

Fig. 4. (a) Cyclic voltammograms recorded during the electroreduction of isopropanol adsorbates in $0.1 \mathrm{M} \mathrm{HClO}_{4}$ on porous $\mathrm{Pt}\left(v=0.01 \mathrm{~V} \mathrm{~s}^{-1}\right)$ : - first cycle; $--\ldots$ second cycle;... third and fourth cycles. (b) Mass signal cyclic voltammograms for $m / z=44\left(\left[\mathrm{C}_{3} \mathrm{H}_{8}\right]^{+}\right)$; the numbers on the curves denote the cycle number.

$\mathrm{V} \mathrm{s}$, whereas for $E_{\text {ad }}=0.35 \mathrm{~V}$ only $65 \%-70 \%$ of the charge is lost (Table 1). Otherwise, the electroreduction of adsorbed residues in $\mathrm{H}_{2} \mathrm{SO}_{4}$ turns out to be more difficult; thus in this acid only $43 \%$ of the charge is lost after four similar potential cycles and the charge decreases continuously on further cycles.

\subsection{3. $H-D$ exchange during propane formation}

The $\mathrm{H}-\mathrm{D}$ exchange during propane formation was studied in $0.1 \mathrm{M} \mathrm{DClO} \mathrm{D}_{4}+\mathrm{D}_{2} \mathrm{O}$. The mass signals observed cover different $\mathrm{H} / \mathrm{D}$ stoichiometry ratios resulting from the H-D exchange (Fig. 5). Thus propane species with partial $\mathrm{H} / \mathrm{D}$ exchange ratios lying between $3\left(\mathrm{C}_{3} \mathrm{H}_{5} \mathrm{D}_{3}\right.$ $(m / z=47))$ and $8\left(\mathrm{C}_{3} \mathrm{D}_{8}(m / z=52)\right)$ are formed. Unfortunately, the $m / z=45$ and $m / z=46$ signals, which correspond to $\mathrm{C}_{3} \mathrm{H}_{7} \mathrm{D}$ and $\mathrm{C}_{3} \mathrm{H}_{6} \mathrm{D}_{2}$ respectively, cannot be considered because they are superimposed on those ex-

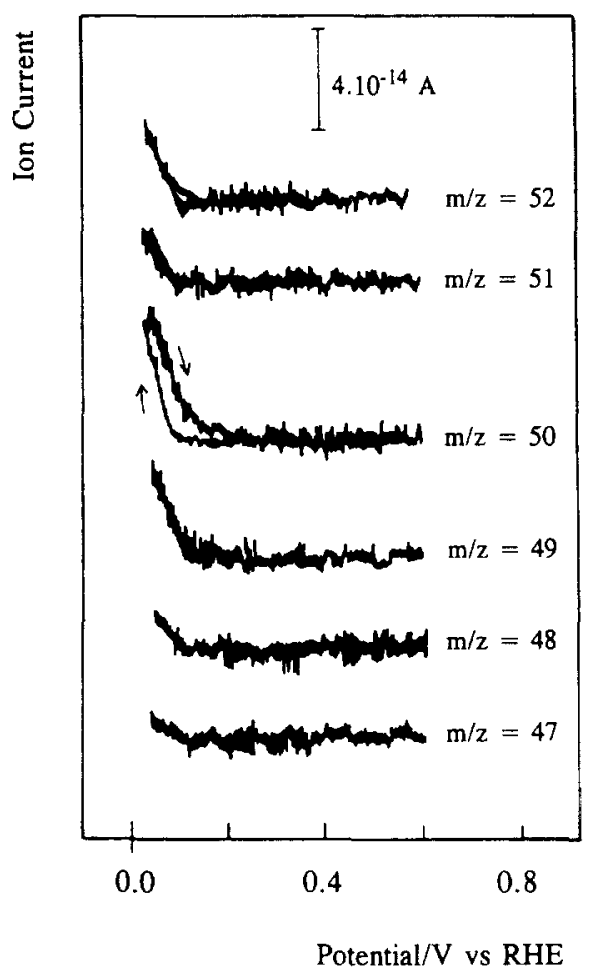

Fig. 5. Mass signal cyclic voltammograms recorded during the electroreduction of $0.05 \mathrm{M}$ isopropanol in $0.1 \mathrm{M} \mathrm{DClO}_{4}+\mathrm{D}_{2} \mathrm{O}$ on porous $\mathrm{Pt}$ $\left(v=0.01 \mathrm{~V} s^{-1}\right)$ for $m / z=47\left(\left[\mathrm{C}_{3} \mathrm{H}_{5} \mathrm{D}_{3}\right]^{++}\right), m / z=48$ $\left(\left[\mathrm{C}_{3} \mathrm{H}_{4} \mathrm{D}_{4}\right]^{+}\right), m / z=49\left(\left[\mathrm{C}_{3} \mathrm{H}_{3} \mathrm{D}_{5}\right]^{+}\right), m / z=50\left(\left[\mathrm{C}_{3} \mathrm{H}_{2} \mathrm{D}_{6}\right]^{++}\right)$, $m / z=51\left(\left[\mathrm{C}_{3} \mathrm{HD}_{7}\right]^{+}\right)$and $m / z=52\left(\left[\mathrm{C}_{3} \mathrm{D}_{8}\right]^{+}\right)$.

pected from isopropanol fragments. The mass distribution exhibits a maximum value for $\mathrm{C}_{3} \mathrm{H}_{2} \mathrm{D}_{6}$ fragments (Fig. 6). The H/D stoichiometry distribution related to propane formation suggests that $H / D$ substituted propanes are formed by a stepwise $\mathrm{H}-\mathrm{D}$ exchange process, presumably involving equilibrium reactions. Similar results have been

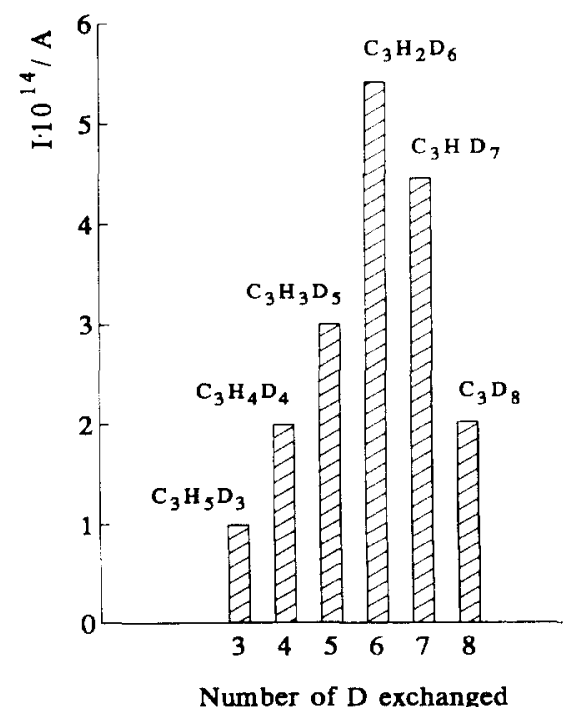

Fig. 6. Relative abundance of various isotopic isomers of propane. Data derived from Fig. 5. 
observed for the electroreduction of acetone [20] and ethanol [21] on Pt in acids. Hence the H-D exchange reactions occurring during propane formation should involve an adsorbate bonded to the surface through the $\mathrm{C} \alpha$ atom.

\subsection{FTIR results}

\subsubsection{Bulk experiments}

For the study of soluble oxidation products, the potential was set at $E=0.20 \mathrm{~V}$ in the base solution and then isopropanol was admitted to the cell. A reference spectrum $R_{0}$ was run at $0.20 \mathrm{~V}$, and then, sample spectra $R$ were measured at various preset potentials. Finally, the reflectance ratio $R / R_{0}$ was calculated. Thus positive bands in the spectra were associated with species consumption and negative bands with species formation at the sampling potential.

Spectra obtained at different potentials with p-polarized light in the presence of isopropanol (Fig. 7) show positive bands at 2978, 1468,1386, 1305, 1166 and $946 \mathrm{~cm}^{-1}$, which indicate isopropanol consumption in the thin layer of solution between the electrode and the IR window. These bands constitute the fingerprint for isopropanol in aqueous solution (Fig. 8(a)). The negative bands at 1697, 1426,1367 and $1238 \mathrm{~cm}^{-1}$ correspond to the formation of acetone, as seen by comparison with the IR transmittance spectrum (Fig. 8(b)). The negative band at $2343 \mathrm{~cm}^{-1}$ is
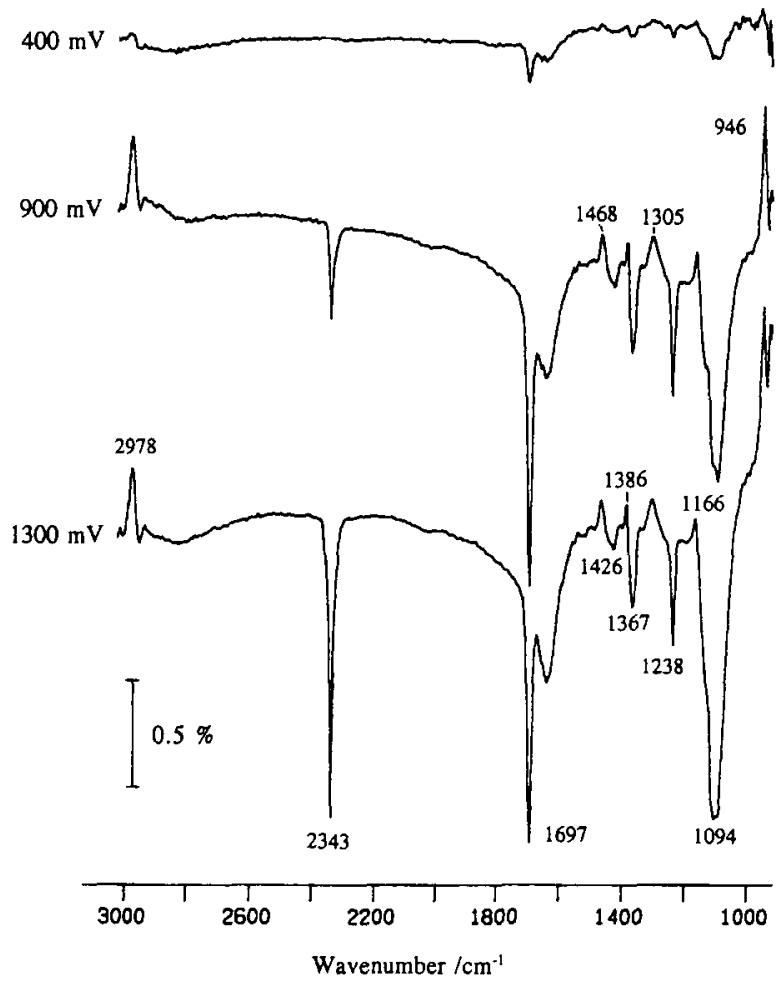

Fig. 7. FTIR reflectance spectra of polycrystallinne $\mathrm{Pt}$ in $0.1 \mathrm{M}$ isopropanol $+0.1 \mathrm{M} \mathrm{HClO}_{4}$. All spectra (256 scans each, $8 \mathrm{~cm}^{-1}$ resolution) are normalized to the reference spectrum collected at $0.20 \mathrm{~V}$.
A
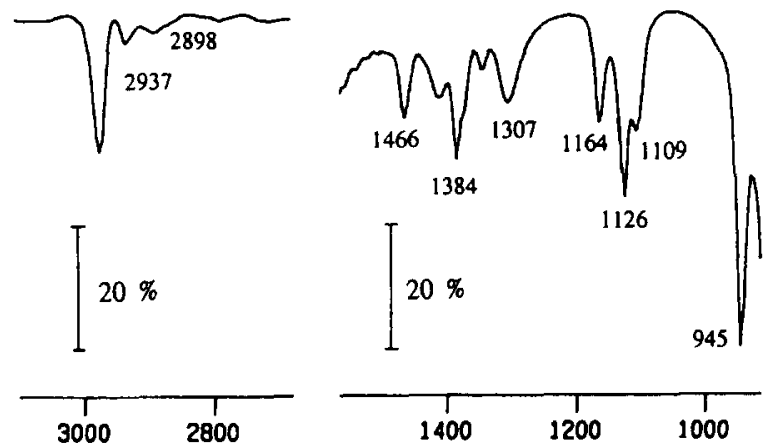

Wavenumber $/ \mathrm{cm}^{-1}$

B

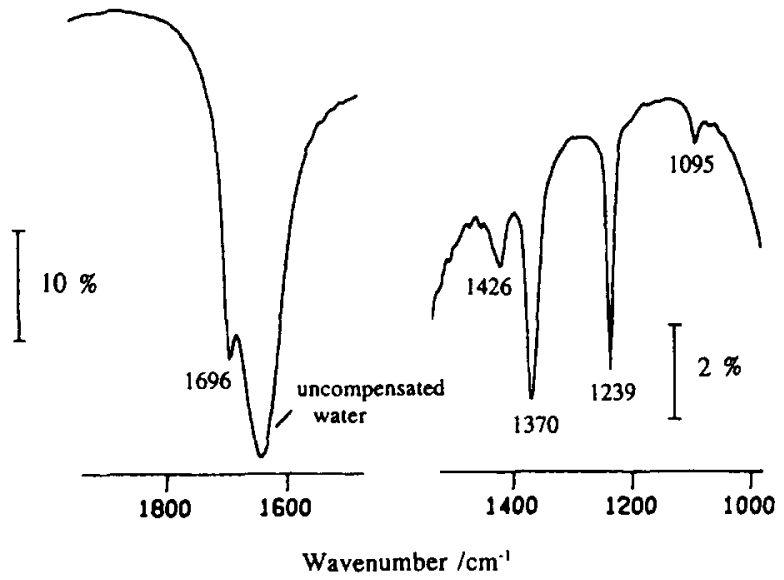

Fig. 8. Transmittance spectrum of (A) $1 \mathrm{M}$ isopropanol and (B) $1 \mathrm{M}$ acetone with a background spectrum of water.

due to the production of $\mathrm{CO}_{2}$, and that at $1094 \mathrm{~cm}^{-1}$ corresponds to $\mathrm{ClO}_{4}^{-}$ions in the solution. All these bands are also present in spectra taken with s-polarized light, as expected for solution species.

It can be seen that the IR bands associated with acetone formation are already present at $0.40 \mathrm{~V}$ and that the intensity of these bands increases at more positive potentials, in agreement with the behaviour of the $m / z=58$ signal (Fig. 1(b)). However, the mass signal shows a decrease in the production of acetone on increasing the potential from 0.90 to $1.30 \mathrm{~V}$, but curiously the intensity of the corresponding IR bands remains almost the same. This could be due to a very slow diffusion of products from the thin layer to the solution, where they remain nearly trapped in the cell space for the duration of the experiment.

As far as the $\mathrm{CO}_{2}$ production is concerned, none is detected at $E=0.40 \mathrm{~V}$, but at $E>0.40 \mathrm{~V} \mathrm{CO}_{2}$ formation increases with the applied potential as expected.

FTIR spectra of acetone are influenced by the isopropanol concentration as seen at $E=1.30 \mathrm{~V}$ for example (Fig. 9). This result confirms the assumption that acetone originates from the electro-oxidation of bulk isopropanol. In contrast, the production of $\mathrm{CO}_{2}$, followed by the inten- 

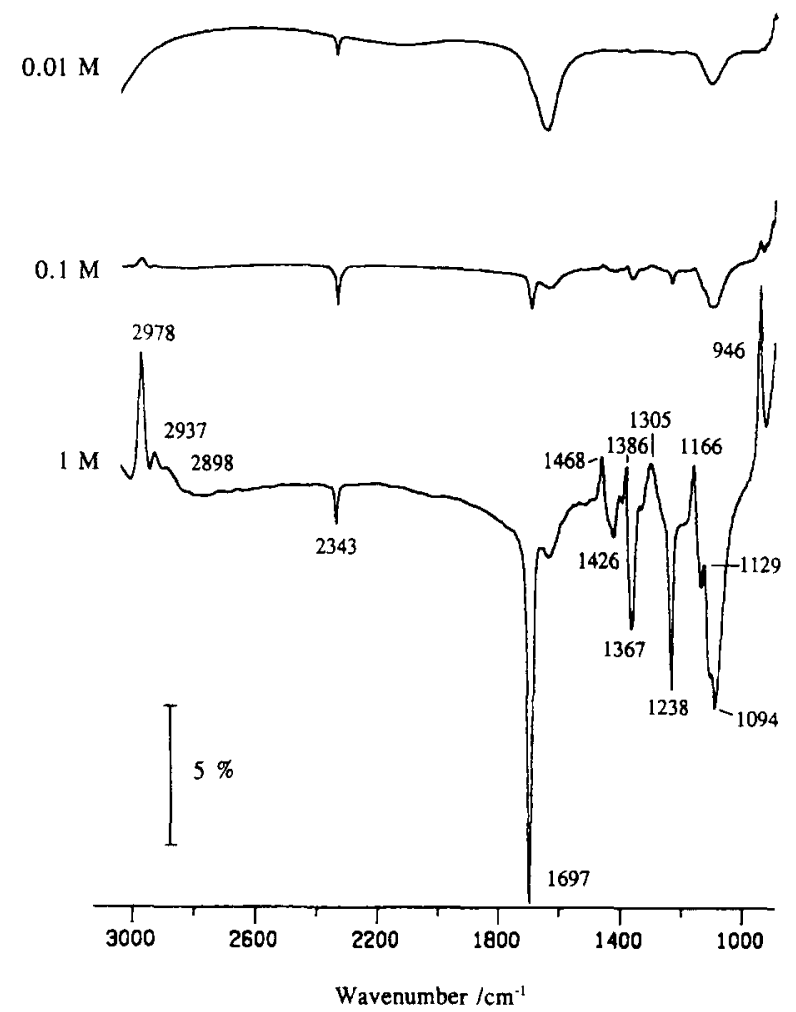

Fig. 9. Comparison of FTIR spectra (256 scans each, $8 \mathrm{~cm}^{-1}$ ) for 0.01 $\mathrm{M}, 0.1 \mathrm{M}$ and $1 \mathrm{M}$ isopropanol in $0.1 \mathrm{M} \mathrm{HClO}_{4}$ at $1.30 \mathrm{~V}$. Reference spectrum recorded at $0.20 \mathrm{~V}$.

sity of the absorption band at $2343 \mathrm{~cm}^{-1}$, shows little sensitivity to the isopropanol concentration; it increases by only a factor of 2.5 as the isopropanol concentration is changed by a factor of 100 . This indicates that $\mathrm{CO}_{2}$ originates from the adsorbates rather than from the deprotonation of acetone. Similar conclusions have been derived from the electro-oxidation of other $\mathrm{C}_{2}$ and $\mathrm{C}_{3}$ alcohols on Pt $[1,2,21]$. These results contrast with the successive dehydrogenation mechanism involving isopropanol, acetone and $\mathrm{CO}_{2}$ recently proposed for the electro-oxidation of isopropanol on $\mathrm{Pt}$ in acid [14].

Finally, the absence from the IR spectra of both the CO adsorbate band in the $2050-2000 \mathrm{~cm}^{-1}$ range and other well-known spectral features of adsorbates containing $\mathrm{C}-\mathrm{H}$ groups in the $2800-3000 \mathrm{~cm}^{-1}$ should be emphasized. As pointed out earlier, the positive bands in this spectral region correspond to the consumption of bulk isopropanol.

\subsubsection{Adsorbed species}

The procedure for obtaining absolute IR absorption bands of adsorbates adopted in this work was the same as that described previously for investigating the electro-adsorption of other alcohols on $\mathrm{Pt}$ in acids [1-3,21]. For isopropanol, $E_{\text {ad }}=0.30 \mathrm{~V}$ was chosen to avoid the influence of reduction and oxidation processes during adsorption. After isopropanol adsorption and solution replacement by $0.1 \mathrm{M} \mathrm{HClO}_{4}$, the reference spectrum $R_{0}$ was taken at $E_{\text {ad }}=0.30 \mathrm{~V}$. Subsequently, the adsorbate was oxidized by a potential step to $E=1.50 \mathrm{~V}$, and finally the potential was reset to $E_{\text {ad }}$ where the sample spectrum $R$ was measured. Spectra are displayed in terms of the ratio $R / R_{0}$, and the spectral features associated with adsorbates correspond to positive bands.

The FTIR spectrum of isopropanol adsorbates (Fig. 10) shows two positive bands at 2962 and $1261 \mathrm{~cm}^{-1}$. The intensities of these bands are about four times the level of
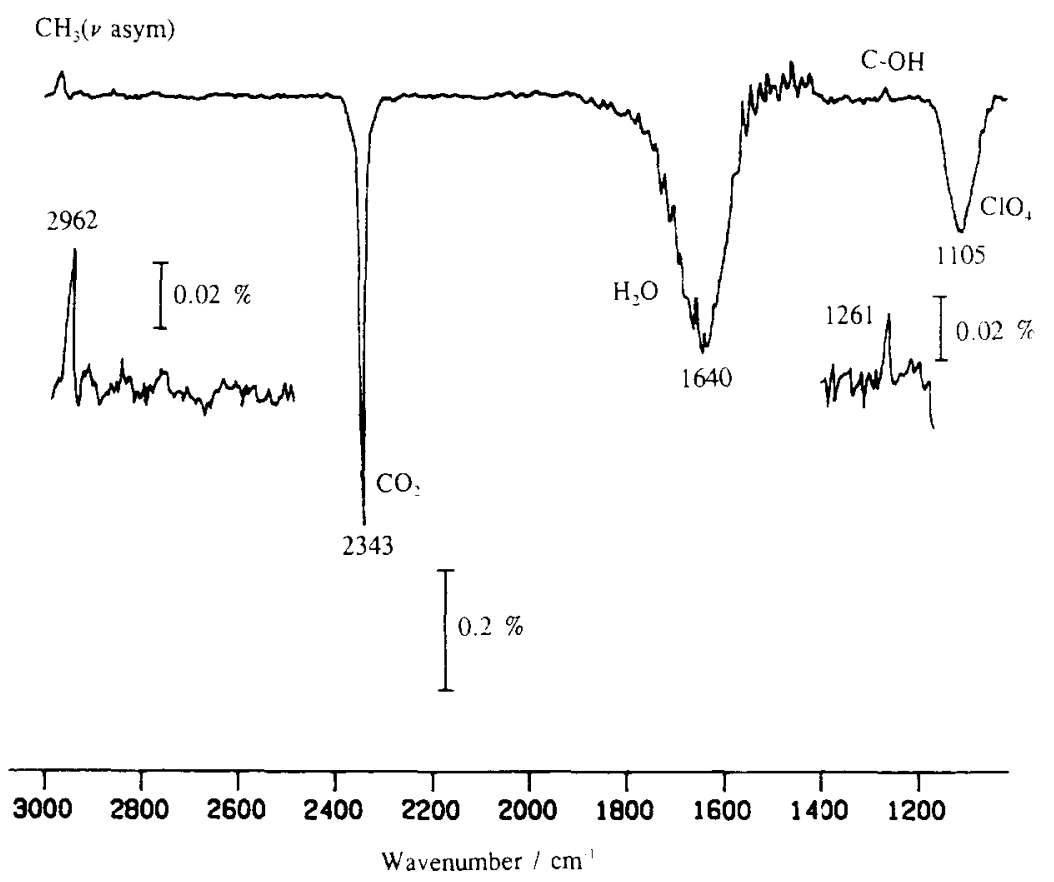

Fig. 10. Reflectance spectrum ( 1000 scans, $\left.8 \mathrm{~cm}^{-1}\right)$ for the strongly adsorbed species of isopropanol $\left(E_{\mathrm{ad}}=0.35 \mathrm{~V}\right)$. 
the noise in the corresponding frequency region, and therefore can undoubtedly be assigned to adsorbed species. As expected, the intensities and shapes of these features are similar to those observed for ethanol adsorbates [21]. Spectra using s-polarized light do not show these contributions, thus confirming the assignment to adsorbates.

The feature at $2962 \mathrm{~cm}^{-1}$ corresponds to the asymmetric stretching vibrations of $\mathrm{CH}_{3}$ [22], and the second feature at $1261 \mathrm{~cm}^{-1}$ is assigned to the $\mathrm{C}-\mathrm{O}$ stretching vibration of species containing a $-\mathrm{COH}$ group [22,23]. The lack of bands in the $2000-2050 \mathrm{~cm}^{-1}$ region confirms the absence of $\mathrm{CO}$ adsorbates. The negative band at 2343 $\mathrm{cm}^{-1}$ is due to $\mathrm{CO}_{2}$ produced at $E=1.50 \mathrm{~V}$, and the band at $1105 \mathrm{~cm}^{-1}$ corresponds to $\mathrm{ClO}_{4}^{-}$ions. The band around $1640 \mathrm{~cm}^{-1}$ is due to uncompensated water.

\section{Discussion}

\subsection{Possible reactions related to adsorbate formation}

The interaction of isopropanol dissolved in acid solution with a Pt electrode surface leads to physisorbed $\left(\mathrm{CH}_{3}-\right.$ $\mathrm{CHOH}-\mathrm{CH}_{3}$ )Pt molecular species. However, for $E>0.05$ $\mathrm{V}$, isopropanol adsorption on $\mathrm{Pt}$ is better described as an electro-adsorption process, as can be concluded from the potentiostatic current transients (see Section 3.1.2). This electro-adsorption process can be interpreted as a dehydrogenation of the molecule at the $\mathrm{C} \alpha$ atom yielding the adsorbate $\mathrm{A}$ which is bound to Pt surface through the $\mathrm{C} \alpha$ atom:

$$
\begin{gathered}
\left(\mathrm{CH}_{3}-\mathrm{CHOH}-\mathrm{CH}_{3}\right) \mathrm{Pt} \\
\stackrel{\left(\mathrm{CH}_{3}-\mathrm{COH}-\mathrm{CH}_{3}\right) \mathrm{Pt}+\mathrm{H}^{+}+\mathrm{e}^{-}}{\mathrm{A}}
\end{gathered}
$$

However, in the $0.05-0.40 \mathrm{~V}$ region in which reaction (1) takes place the Pt surface is largely covered by $\mathrm{H}$ atoms, and therefore interactions between the adsorbate $A$ and $\mathrm{H}$ adatoms should be considered. For instance, the hydrogenolysis of adsorbate A can occur through reactions such as:

$$
\begin{gathered}
\left(\mathrm{CH}_{3}-\mathrm{COH}-\mathrm{CH}_{3}\right) \mathrm{Pt}+2(\mathrm{H}) \mathrm{Pt} \\
\mathrm{A} \\
\longrightarrow\left(\mathrm{CH}_{3}-\mathrm{CH}-\mathrm{CH}_{3}\right) \mathrm{Pt}+\mathrm{H}_{2} \mathrm{O}+2 \mathrm{Pt} \\
\mathrm{B}
\end{gathered}
$$

or

$$
\begin{gathered}
\left(\mathrm{CH}_{3}-\mathrm{COH}-\mathrm{CH}_{3}\right) \mathrm{Pt}+(\mathrm{H}) \mathrm{Pt} \\
\mathrm{A} \\
\longrightarrow \underset{\mathrm{C}}{\left(\mathrm{CH}_{3}-\mathrm{C}-\mathrm{CH}_{3}\right) \mathrm{Pt}+\mathrm{H}_{2} \mathrm{O}+\mathrm{Pt}}
\end{gathered}
$$

Reactions (2) and (3) yield adsorbates $B$ and $C$ respectively. The occurrence and relative distribution of $A, B$ and $C$ should, in principle, depend on the degree of coverage by $\mathbf{H}$ adatoms. Accordingly, we should expect distinct electro-oxidation reactions for each adsorbate. In fact, as $E_{\text {ad }}$ is increased from 0.25 to $0.35 \mathrm{~V}$, the amount of adsorbate $A$, which maintains the $\mathrm{OH}$ group, should increase and its electro-oxidation should become more facile than that of B and C. A further deprotonation of adsorbate $A$ leads to the formation of an acetone-type adsorbate (adsorbate D):

$$
\begin{gathered}
\left(\mathrm{CH}_{3}-\mathrm{COH}-\mathrm{CH}_{3}\right) \mathrm{Pt} \\
\mathrm{A} \\
\longrightarrow \underset{\mathrm{D}}{\left(\mathrm{CH}_{3}-\mathrm{CO}-\mathrm{CH}_{3}\right) \mathrm{Pt}+\mathrm{H}^{+}+\mathrm{e}^{-}}
\end{gathered}
$$

The formation and relative distribution of adsorbates A-D on Pt can be determined from the experimental data. Thus the presence of adsorbate $A$ produced by reaction (1) agrees with the $-\mathrm{CH}_{3}$ and $-\mathrm{COH}$ bands found in the IR spectrum (Fig. 9). The fact that adsorbates formed at $E_{\mathrm{ad}}=0.35 \mathrm{~V}$ can be electro-oxidized more easily than those produced at $E_{\text {ad }}=0.25 \mathrm{~V}$ (Fig. 2) provides further support for the predominance of adsorbate $A$ as $E_{\text {ad }}$ is increased. However, the presence of only adsorbate A cannot explain the rather simple stepwise reaction pathway for the $\mathrm{H}-\mathrm{D}$ exchange observed during propane formation (Figs. 5 and 6).

However, adsorbates $\mathrm{B}$ and $\mathrm{C}$ would also contribute to the appearance of the $\mathrm{CH}_{3}$ stretch in the IR spectrum (Fig. 9). If this is the case, a band associated with the $\mathrm{CH}$ vibration should also be observed in the IR spectrum related to adsorbate $B$. Despite the fact that the $\mathrm{C}-\mathrm{H}$ stretching band is weak, so that the detection of small amounts of adsorbate B using the IR spectra is rather difficult, it is reasonable to assume that the presence of adsorbate $\mathrm{C}$ is strongly favored, particularly at low $E_{\mathrm{ad}}$. Nevertheless, the presence of a small amount of adsorbate $B$ cannot be completely excluded. In fact, adsorbates B and $C$ could be involved in a stepwise reaction pathway for the H-D exchange, leading to the formation of propane. Then the $\mathrm{H}-\mathrm{D}$ exchange mechanism during the production of propane becomes rather similar to that proposed for ethylidyne H-D exchange in the gas phase [24].

Finally, although there is no direct evidence for the presence of adsorbate $\mathrm{D}$, its formation allows some experimental facts to be explained. The electroreduction of adsorbed acetone to propane seems to be more difficult than that of adsorbates $A-C$. Therefore adsorbate D may be the residue remaining on the surface after electroreduction by potential cycling in the hydrogen region (Fig. 3, dashed line).

RAIRS and HREELS studies of the adsorption of isopropanol on both clean and hydrogen-covered $\mathrm{Pt}(111)$ [25] support the formation of adsorbate D. No formation of $\mathrm{CO}$ or $\mathrm{CH}_{4}$ was detected in these studies, in agreement with the experimental results described in the present paper. For temperatures above $200 \mathrm{~K}$, isopropanol dissociates on a clean $\mathrm{Pt}(111)$ surface to give adsorbed hydrogen and ace- 
tone, whereas preadsorbed hydrogen on $\operatorname{Pt}(111)$ inhibits the decomposition favoring the retention of molecular isopropanol [25]. Thus we should expect the distribution of species A-C, which can be considered similar to isopropanol, or species D (acetone) to depend on the hydrogen coverage of the surface and therefore on the adsorption potential. We propose the presence of an $\eta^{2}$ acetone species, which has both the $\mathrm{C}$ atom and the $\mathrm{O}$ atom in the carbonyl group coordinated to the surface [26,27]. In this case, a $\pi$-bonded $\eta^{2}$ acetone species is possible [26] and consequently the $\mathrm{C}=\mathrm{O}$ stretch of a carbonyl group around $1700 \mathrm{~cm}^{-1}$ should not be observed as the corresponding vibrational transition is forbidden by the surface selection rule. This assumption could explain the absence of the band corresponding to a carbonyl group from adsorbate D in the spectrum of Fig. 10.

\subsection{Electroreduction and electro-oxidation processes}

The production of propane (Fig. 4) can be explained through the electroreduction of adsorbates $\mathrm{A}-\mathrm{C}$ as follows:

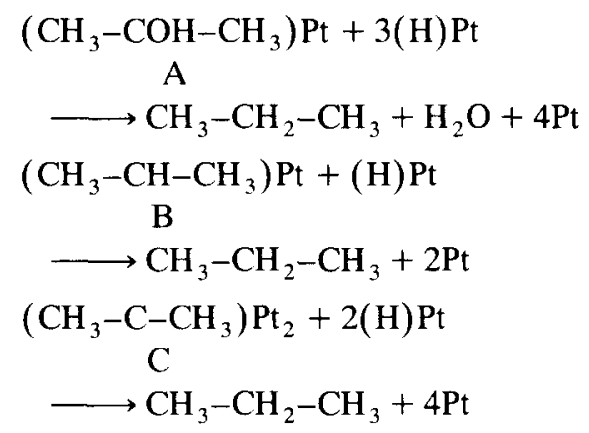

In contrast with adsorbates $\mathrm{A}-\mathrm{C}$, adsorbate $\mathrm{D}$ apparently remains on the Pt surface after potential cycling in the $\mathrm{H}$ adatom potential range as already discussed (Fig. 3).
As far as the electro-oxidation products are concerned, $\mathrm{CO}_{2}$ is produced through the electro-oxidation of adsorbates A-D. After electroreduction of the adsorbates by potential cycling in the $\mathrm{H}$ adatom potential range, only adsorbate D exclusively remains on the Pt surface and it can be electro-oxidized in the same potential range as acetone [20]. This fact strongly supports the idea that adsorbate $\mathbf{D}$ and adsorbed acetone on Pt probably have the same structure.

Since adsorbates A-D keep the original $\mathrm{C}_{3}$ chain of isopropanol, it is reasonable to assume that partially oxidized fragments are formed from adsorbates by potential cycling in the platinum oxide potential range. The complete electro-oxidation of these fragments requires rather prolonged potential cycling between $E_{\text {ad }}$ and $1.5 \mathrm{~V}$ at 0.01 $\mathrm{V} \mathrm{s}^{-1}$ (Fig. 3).

When isopropanol is present in the bulk of the solution, acetone can be detected as the final product. The electrooxidation of isopropanol to acetone starts at a rather low potential $(E=0.35 \mathrm{~V})$. Reaction (4) implies the formation of adsorbate $D$ from the deprotonation of adsorbate A. Adsorbate $\mathrm{D}$ can be attached to the surface through a $\pi$-bonding interaction with $\mathrm{Pt}$, although the corresponding bond strength would be lower than those for adsorbates A, $\mathrm{B}$ and $\mathrm{C}$. Therefore when isopropanol is present in the bulk of the solution, the following competitive adsorption displacement is likely to occur:

$$
\begin{aligned}
& \left(\mathrm{CH}_{3}-\mathrm{CO}-\mathrm{CH}_{3}\right) \mathrm{Pt}+\mathrm{CH}_{3}-\mathrm{CHOH}-\mathrm{CH}_{3} \\
& \stackrel{\mathrm{D}}{\longrightarrow} \mathrm{CH}_{3}-\mathrm{CO}-\mathrm{CH}_{3}+\left(\mathrm{CH}_{3}-\mathrm{CHOH}-\mathrm{CH}_{3}\right) \mathrm{Pt}
\end{aligned}
$$

This reaction explains why acetone can be detected when isopropanol is present in the bulk of the solution but not from adsorbates. Furthermore, the isopropanol adsorbate

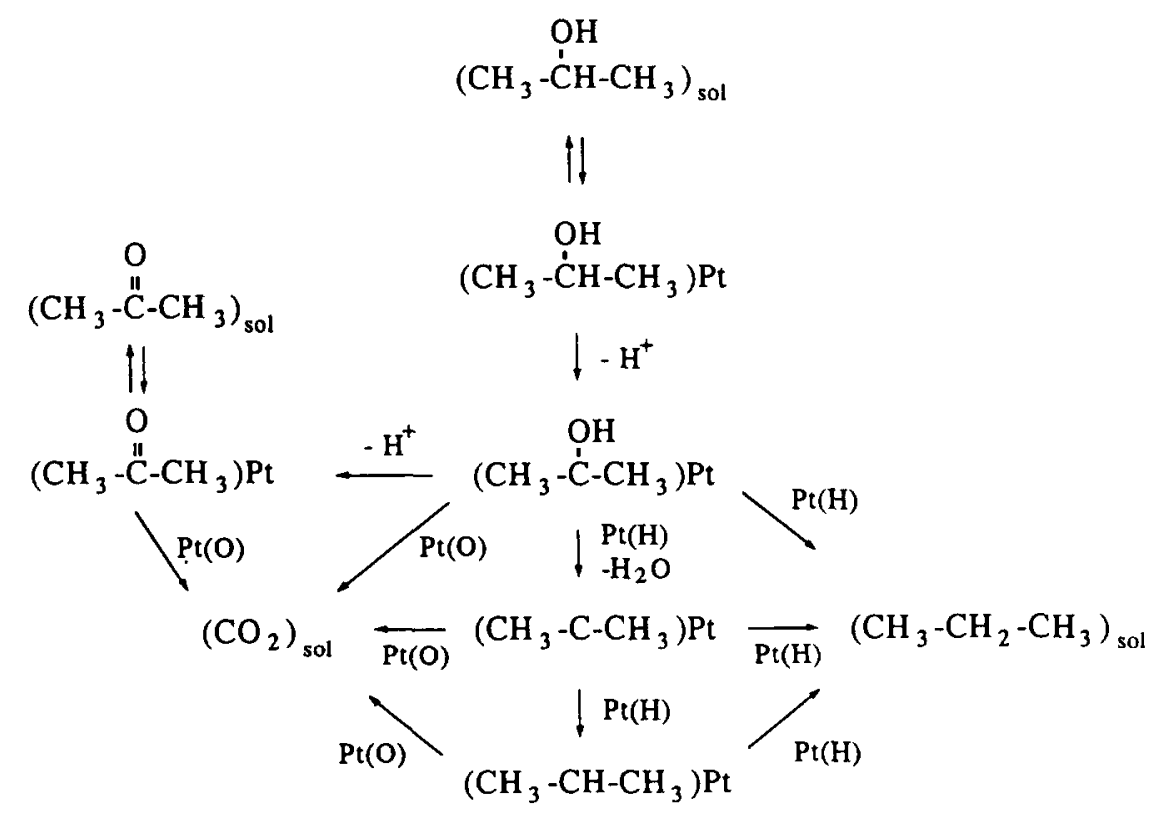

Fig. 11. Reaction pathways involved in electrochemical reactions of isopropanol at Pt electrodes in acid solutions in the $0.05-1.50 \mathrm{~V}$ potential range at $25^{\circ} \mathrm{C}$. 
formed in reaction (8) undergoes further reactions to form strongly adsorbates $\mathrm{A}, \mathrm{B}$ and $\mathrm{C}$.

The electrochemical reactions of isopropanol adsorbates on $\mathrm{Pt}$ in acid solution in the range $0.05-1.50 \mathrm{~V}$ are summarized in Fig. 11.

\subsection{Comparison between the electrochemical reaction pathways for isopropanol and propanol on Pt in acid}

The electrochemical behavior of isopropanol on $\mathrm{Pt}$ can be compared with that of propanol, which was discussed in a previous paper [1]. Propanal, propionic acid and $\mathrm{CO}_{2}$ are the main electro-oxidation products of propanol, whereas acetone and $\mathrm{CO}_{2}$ are produced from isopropanol. In both cases the production of $\mathrm{CO}_{2}$ is related to the presence of strongly adsorbed species originated from each alcohols. Products maintaining the $\mathrm{C}_{3}$ structure of the original molecules are related to the bulk electro-oxidation of alcohols and imply that the $\mathrm{C} \alpha$ atom is the reactive center.

Remarkable differences in the electroreduction reactions are also observed. In contrast with isopropanol, which only forms propane, propanol yields propane and ethane in a yield ratio of $1: 3$. This fact suggests that the presence of the $\mathrm{OH}$ group in the primary alcohol strongly favors rupture of the $\mathrm{C}_{3}$ chain during electroreduction, yielding hydrocarbon-type adsorbates with $\mathrm{C}_{2}$ and $\mathrm{C}_{3}$ chains. Otherwise, rupture of the carbon chain is impeded when the $\mathrm{OH}$ group is attached to the central $\mathrm{C}$ atom of isopropanol.

The absence of $\mathrm{CO}$ adsorbates for the case of isopropanol adsorption indicates another important difference in adsorption behavior on Pt for isopropanol and propanol. Accordingly, the favorable trend to chain fragmentation of primary alcohols upon adsorption on $\mathrm{Pt}$, leading to a considerable Pt surface coverage by $\mathrm{CO}$-like adsorbates in contrast with secondary alcohols, is quite remarkable.

The electro-oxidation of adsorbates from propanol and isopropanol to $\mathrm{CO}_{2}$ occurs in a distinct potential range. Thus, for isopropanol, $\mathrm{CO}_{2}$ production during adsorbate electro-oxidation shows a maximum at $1.04 \mathrm{~V} / \mathrm{RHE}$ whereas for propanol the greatest contribution appears at $0.73 \mathrm{~V} / \mathrm{RHE}$. This fact is consistent with the various adsorbate structures already discussed for each alcohol.

Finally, it should be mentioned that adsorbates from isopropanol are largely desorbed during potential cycling in the $\mathrm{H}$ adatom potential range. Although a similar effect has been reported for adsorbates from propanol, the electroreduction of these residues occurs to a minor extent presumably because of the presence of $\mathrm{CO}$-like species.

\section{Acknowledgements}

Financial support from the Gobierno de Canarias under Research Contract $218 / 92$ is gratefully acknowledged.
The authors wish to thank Dr. T. Iwasita for helpful discussions. The authors are indebted to Professor Dr. W. Vielstich for permission to work in the laboratory of the Institut für Physikalische Chemie der Universität Bonn and for his continuous encouragement during this work.

\section{References}

[1] E. Pastor, S. Wasmus, T. Iwasita, M.C. Arevalo, S. Gonzalez and A.J. Arvia, J. Electroanal. Chem., 350 (1993) 97.

[2] E. Pastor, S. Wasmus, T. Iwasita, M.C. Arevalo, S. Gonzalez and A.J. Arvia, J. Electroanal. Chem., 353 (1993) 81.

[3] E. Pastor, S. Wasmus, T. Iwasita, M.C. Arevalo, S. Gonzalez and A.J. Arvia, J. Electroanal. Chem., 371 (1994) 167.

[4] A. Bewick and S. Pons, in R.J.H. Clark and R.E. Hester (Eds.), Advances in Infrared and Raman Spectroscopy, Vol. 12, Heyden, London, 1985, Ch. 1.

R.J. Nichols, in J. Lipkowski and P.N. Ross (Eds.), Structure of Electrified Interfaces, VCH, Weinheim, 1993, Ch.7.

[5] O. Wolter and H. Heitbaum, Ber. Bunsenges. Phys. Chem., 88 (1984) 6.

B. Bittins-Cattaneo, E. Cattaneo, P. Königshoven and W. Vielstich, in A.J. Bard (Ed.), Electroanalytical Chemistry: A Series of Advances, Vol. 17, Dekker, New York, 1991, p. 181.

[6] V.E. Kazarinov and S.V. Dolidze, Elektrokhimiya, 9 (1973) 1183.

[7] G. Horanyi, G. Vertes and P. König, Z. Phys. Chem., 254 (1973) 198.

[8] E. Sokolova, Electrochim. Acta, 20 (1975) 323.

[9] S.N. Raicheva, M.V. Christov and E.I. Sokolova, Electrochim. Acta, 26 (1981) 1669.

[10] E.I. Sokolova and M.V. Christov, J. Electroanal. Chem., 175 (1984) 195.

[11] P.T.A. Sumodjo, E.J. da Silva and T. Rabockai, J. Electroanal. Chem., 271 (1989) 305.

[12] L.W.H. Leung, S.C. Chang and M. Weaver, J. Electroanal. Chem., 266 (1989) 317.

[13] L.W.H. Leung and M. Weaver, Langmuir, 6 (1990) 323.

[14] S.G. Sun, D.F. Yang and Z.W. Tian, J. Electroanal. Chem., 289 (1990) 177.

[15] S.G. Sun and Y. Lin, J. Electroanal. Chem., 375 (1994) 401.

[16] P. Gao, C.H. Lin, C. Shannon, G.N. Salaita, J.H. White, S.A. Chaffins and A. Hubbard, Langmuir, 7 (1991) 1515.

[17] Th. Hartung, Ph.D. Thesis, Witten/Herdecke University, 1989.

[18] T. Iwasita, F.C. Nart and W. Vielstich, Ber. Bunsenges. Phys. Chem., 94 (1990) 1030.

[19] E. Stenhagen, S. Abrahamsson and F.W. McLaffeerty (Eds.), Atlas of Mass Spectral Data, Interscience, New York, 1969.

[20] B. Bänsch, Th. Hartung, H. Baltruschat and J. Heitbaum, J. Electroanal. Chem., 259 (1989) 207.

[21] E. Pastor and T. Iwasita, Electrochim. Acta, 39 (1994) 547.

[22] G. Socrates, Infrared Characteristic Group Frequencies, Wiley, New York, 1980.

[23] T. Iwasita, F.C. Nart, B. López and W. Vielstich, Electrochim. Acta, 37 (1992) 2361.

[24] B.E. Koel, B.E. Bent and G.A. Somorjai, Surf. Sci., 146 (1984) 211.

[25] M.A. Vannice, W. Erley and H. Ibach, Surf. Sci., 254 (1983) 12.

[26] N.R. Avery, Surf. Sci., 125 (1983) 771.

[27] M.A. Vannice, W. Erley and H. Ibach, Surf. Sci., 254 (1983) 1. 